\title{
Availability and components of maternity services according to providers and users perspectives in North Gondar, northwest Ethiopia
}

\author{
Abebaw Gebeyehu Worku*, Alemayehu Worku Yalew² and Mesganaw Fantahun Afework ${ }^{3}$
}

\begin{abstract}
Background: The goal of reducing maternal mortality can be achieved when women receive important service components at the time of their maternity care. This study attempted to assess the availability and the components of maternity services according to the perspectives of service users and providers.

Method: A linked facility and population-based survey was conducted over three months (January to March 2012) in North Gondar Zone. Twelve kebeles (clusters) were selected randomly from six districts to identify maternity clients cared for by skilled providers. Then 12 health centers and 3 hospitals utilized by the corresponding cluster population were selected for facility survey. Interview with facility managers/heads, providers and clients and observations were used for data collection. Data were entered using Epi Info and were exported to SPSS software for analysis.

Results: Antenatal and delivery care were available in most of the visited facilities. However, the majority of them were not fully functioning for EmOC according to their level. Signal functions including administration of anticonvulsants and assisted vaginal delivery were missing in seven and five of the 12 health centers, respectively. Only one hospital met the criteria for comprehensive emergency obstetric care (performed cesarean section). Only 24\% of the providers used partograph consistently. About 538 (32.3\%) and 231 (13.8\%) of the women received antenatal and delivery care from skilled providers, respectively. Most of the services were at health centers by nurses/midwives. At the time of the antenatal care, women received the important components of the services (percentage of users in bracket) like blood pressure checkup (79\%), urine testing (35\%), tetanus immunization (45\%), iron supplementation (64\%), birth preparedness counseling (51\%) and HIV testing (71\%). During delivery, $80 \%$ had their blood pressure measured, $78 \%$ were informed on labor progress, $89 \%$ had auscultation of fetal heartbeat, $80 \%$ took drugs to prevent bleeding and $78 \%$ had counseling on early \& exclusive breast-feeding.

Conclusion: Antenatal and delivery care were available in most of the visited facilities. However, important components of both the routine and emergency maternity care services were incomplete. Improving the functional capacity of health facilities for the delivery of routine maternity and EmOC services are needed.
\end{abstract}

Keywords: Availability of maternal service, Components of maternity care

\footnotetext{
* Correspondence: gabebaw2worku@gmail.com

'Department of Reproductive Health, Institute of Public Health, University of

Gondar, Gondar, Ethiopia

Full list of author information is available at the end of the article
} 


\section{Background}

Utilization of maternal health services by skilled providers, a proximate indicator of maternal survival, is very low in Ethiopia. According to the recent (2011) Ethiopian Demographic and Health Survey (EDHS) report, only 34\%, 10\% and $6 \%$ women have antenatal (ANC), delivery, and postnatal care by a skilled provider, respectively [1].

One of the key factors for the utilization of skilled maternal care is access to and availability of health care facilities. Evidences from many developing countries, including Mali, South Africa, Zambia, Paraguay, Uganda and Tanzania indicate that the proximity of maternal health services to users and a reliable transportation system to link the community and health facilities are critical for maternal service utilization [2-5]. The availability of basic and comprehensive emergency obstetric care (signal functions) in a health care system are crucial for maternal survival [6]. Signal functions, including parenteral antibiotics, anticonvulsants and oxytocics, manual removal of placenta, removal of retained products, assisted vaginal delivery and neonatal resuscitation (at basic emergency obstetric care facility) with the addition of cesarean delivery and blood transfusion (at comprehensive emergency obstetric care facility) used to treat direct obstetric complications cause the majority of maternal deaths [7].

In order to have a better health care access, Ethiopia has introduced a three-tier health care delivery system. The first level is the primary health care unit or district health system comprising a primary (district) hospital (to cover 60,000-100,000 people), health centers $(1 / 15,000-25,000$ population), and their satellite health posts connected to each other by a referral system. Level two is a general hospital covering a population of 1-1.5 million people, and level three is a specialized hospital covering a population of 3.5-5 million people [8]. District level facilities are organized to provide obstetric first aid at health post levels with early referral to health centers that can provide basic emergency/essential obstetric care and further referral to district hospitals for comprehensive emergency/essential obstetric care.

Once the mother arrives at the health facility, she has to have access to a medical professional who has the skills and equipment to give the necessary services. However, in many developing countries, health facilities do not perform their expected functions according to their level. For instance, a study on health facilities in 13 countries found out that most hospitals did not provide life saving services fully. In the study, assisted vaginal delivery was missing in $42 \%, 73 \%, 38 \%$, and $19 \%$ of the hospitals in Benin, Mali, Morocco, and Uganda, respectively. The removal of retained products was missing in $12 \%, 9 \%$ and $12 \%$ of the hospitals in Benin, Mali and Morocco, respectively [9]. Similar studies revealed the fact that facilities were not performing what they were supposed to [10].

Studies showed that many facilities suffered from staff training deficiencies that hindered the provision of specific services. In many settings, midlevel providers such as midwives were not trained or authorized to perform some of the key procedures expected from a skilled attendant. A study in Benin, Ecuador, Jamaica, and Rwanda showed a wide gap between current evidence based standards and current levels of provider competence. In the study, providers answered $55.8 \%$ of the knowledge questions and performed $48.2 \%$ of the skills steps correctly $[11,12]$. Pre-service training is also not a guarantee. It is recommended that maternity care providers receive refresher training or updates in midwifery every three to five years [13].

In Ethiopia, many of the previous studies have reported ANC, delivery and postnatal care coverage as utilization of maternal services. However, achieving the goals of maternal health care (reduction in morbidity and mortality) depends more on utilization of important service components (better quality of care) than high coverage of the services. Essential interventions (service components) provided before pregnancy, during pregnancy, delivery, and postpartum are outlined in the WHO documents and lancet article $[14,15]$. In the country, there is limited evidence about specific service components and the performance of health facilities at the time of maternity care. Therefore, the question, "What kind of service is available and is delivered by a skilled provider at the time of maternity care?" needs an appropriate answer for planning as well as, monitoring maternal health services. This study was planned to assess the availability and components of maternity services in both routine and emergency situations according to providers and users perspectives in North Gondar.

\section{Methods}

Two surveys, including the facility survey, to collect information from the providers and clients, and the interviews with the population to gather information from users' were carried out concurrently. As suggested in the manuals [16], the facility survey was linked to the population-based survey sample areas. The study was conducted over three months (January - March 2012) in North Gondar Zone. The zone has 22 'woredas' (districts). According to the figures from the central statistical agency, 2007, this zone had an estimated total population of $2,921,470$, about $84.1 \%$ of which were rural dwellers [17]. In the zone, there is only one referral hospital with a comprehensive emergency obstetric care. There are also about a hundred health centers and two district hospitals. The zone, which is the largest of the region, has a difficult topography. 
In order to get a sufficient number of maternal care users, a total of twelve clusters or kebeles (the lowest administrative units having clear geographical boundary and administrations) were selected randomly from six districts, namely Dembia, Lay Armachiho, West Belessa, Metema, Debark and Dabat. All women who had births one-year preceding the survey and who received maternal care during pregnancy and delivery were included in the sample. Based on 34\% and 10\% coverage of skilled antenatal and delivery care [1], the sample size was determined on the assumption of $95 \%$ confidence level and $4 \%$ of worst acceptable error. In the selected clusters, 538 and 231 of the eligible women were skilled antenatal and delivery care users.

One of the options for sampling facilities in a linked survey is determine the nearest facility, or facilities, to each population-based survey cluster and conduct the facility survey in all identified. In this approach, the sample size is improved by assuring that the number of facilities is no less than the number of population-based clusters. Based on this recommendation, we have identified one basic essential obstetric care facility (health center utilized by the cluster population) for each selected cluster (kebele). Twelve health centers and three hospitals serving the selected kebele population were included for the facility survey. Interview with managers/heads of health institutions and observation were used to collect data related to the availability, readiness, and functioning of facilities for the provision of skilled maternal care. During observation, a checklist containing infrastructure, equipment, drugs and supplies, and laboratory tests was prepared. Based on adequacy and functional status, most of the findings were rated as 0) not available (not functional), 1) available but unsatisfactory and 2) available and functional. In addition, all midlevel skilled care providers who were directly involved in maternity care at these health centers and district hospitals (38 skilled providers) were interviewed about their training and skills for different types of procedures. A skilled attendant is an accredited health professional who has been educated and trained to proficiency in the skills needed to manage normal (uncomplicated) pregnancies, childbirth and the immediate postnatal period, and in the identification, management and referral of complications in women and newborns $[18,19]$. In this study, skilled providers included midwives, nurses, health officers and doctors. Health officers are those trained for four years to get their Bachelors degree and they work as clinician in the rural set up (health centers).

Thirty-six data collectors and supervisors (2 data collectors and 1 supervisor for each kebele) were trained and deployed for identifying and interviewing maternal care users. The interviews were conducted using the local language (Amharic) after the questionnaire was pretested for cultural appropriateness and clarity. To conduct the facility-based survey, 14 experienced health professionals were recruited. After the appropriate coding, the data was entered in Epi Info version 3.5.3 software, and exported to SPSS software for analysis.

Before the commencement of the study, ethical clearance was obtained from the Institutional Review Board of the College of Health Sciences, Addis Ababa University. During data collection, the study participants were asked for consent and informed to interrupt the interview on desire. All participants signed written agreements (consent forms). To ensure confidentiality, names were not used in depicting the results of the study.

\section{Results}

Availability of the routine maternal services at health centers and hospitals

All facilities (hospitals and health centers) reported that they had ANC and family planning (FP) services. Most of the facilities, except one health center, claimed that they had delivery and PMTCT services, but one-fourth of the visited health centers did not have postnatal care in the first 7 days. Five out of the 12 health centers and all hospitals had safe abortion services (Table 1).

However, findings from the interview with skilled maternal care users indicated that out of the 1668 women who gave birth one year preceding the survey, only 538 $(32.3 \%)$ and 231 (13.8\%) received antenatal and delivery care from skilled providers, respectively. Of the total users of the ANC service, $86 \%$ received their care at health centers, and most (92\%) of the users were served by nurses or midwives. Similarly, three-fourths of the births took place at health centers assisted by nurses or midwives.

None of the health centers visited had laboratory services for testing syphilis. Moreover, many health centers did not have laboratory tests for hemoglobin, urine for protienuria, and cross match (Table 1).

\section{Emergency obstetric care signal functions}

A total of five health centers and all three hospitals fulfilled the criteria for signal functions for basic emergency obstetric care, but only Gondar Hospital fulfilled all the signal functions for comprehensive emergency obstetric care. Of the signal functions, parenteral antibiotics and oxytocics were practiced by all the facilities visited except one health center. However, important functions, including the administration of anticonvulsants and assisted vaginal delivery were missing in three-fifths and two-fifths of the health centers, respectively. Only onefourth of the health centers had working ambulances to give referral service (Table 1). 
Table 1 Availability of maternal services and laboratory tests in basic and comprehensive obstetric care facilities (selected health centers and all hospitals) in North Gondar, 2012

\begin{tabular}{|c|c|c|c|}
\hline \multirow{2}{*}{$\begin{array}{l}\text { Type of services available in } \\
\text { the facility }\end{array}$} & \multicolumn{3}{|c|}{ Number of visited facilities } \\
\hline & $\begin{array}{c}\text { Health } \\
\text { centers (12) }\end{array}$ & $\begin{array}{l}\text { Hospitals } \\
\text { (3) }\end{array}$ & $\begin{array}{c}\text { Total } \\
(15)\end{array}$ \\
\hline \multicolumn{4}{|c|}{ Availability of selected maternity related services } \\
\hline Antenatal care & 12 & 3 & 15 \\
\hline Delivery care & 11 & 3 & 14 \\
\hline Postnatal care in the first 7 days & 9 & 3 & 12 \\
\hline Family planning & 12 & 3 & 15 \\
\hline VCT & 10 & 3 & 13 \\
\hline PMTCT & 11 & 3 & 14 \\
\hline Safe abortion & 5 & 3 & 8 \\
\hline $\begin{array}{l}\text { Maternity service for } 24 \mathrm{hrs} \text { and } \\
7 \text { days a week }\end{array}$ & 9 & 3 & 12 \\
\hline $\begin{array}{l}\text { Working ambulance } \\
\text { (referral service) }\end{array}$ & 3 & 2 & 5 \\
\hline \multicolumn{4}{|c|}{ Signal functions to treat major obstetric complications } \\
\hline Parenteral antibiotics & 11 & 3 & 14 \\
\hline Parenteral oxytocics & 11 & 3 & 14 \\
\hline Anticonvulsants & 5 & 3 & 8 \\
\hline Manual removal of placenta & 9 & 3 & 12 \\
\hline Removal of retained products & 10 & 3 & 13 \\
\hline Assisted vaginal delivery & 7 & 2 & 9 \\
\hline Cesarean section & 0 & 1 & 1 \\
\hline Blood transfusion & 0 & 2 & 2 \\
\hline \multicolumn{4}{|c|}{ Availability of selected laboratory tests } \\
\hline Syphilis testing (VDRL) & 0 & 3 & 3 \\
\hline Hemoglobin test & 5 & 3 & 8 \\
\hline Urine test-protienuria & 6 & 3 & 9 \\
\hline Blood film-malaria & 11 & 3 & 14 \\
\hline HIV test & 12 & 3 & 15 \\
\hline Cross match tests & 5 & 2 & 7 \\
\hline
\end{tabular}

Important service components received during antenatal and delivery care

At the time of antenatal care, some women received important components of services (percentage of users in bracket) like blood pressure checkup (79\%), urine testing (35\%) tetanus immunization (45\%), iron supplementation (64\%), birth preparedness counseling (51\%), saving money for possible complication (45.2\%), and HIV testing $(71 \%)$.

Among women who have delivery by a skilled attendant, about $80 \%$ had their blood pressure measured, $78 \%$ informed on labor progress, $89 \%$ had auscultation of fetal heartbeat, $80 \%$ took drugs to prevent bleeding and $78 \%$ had counseling on early \& exclusive breast-feeding.
Weight was measured and vaccine was provided for babies of $67 \%$ and $69 \%$ of mothers, respectively. There are some differences in providing services by type of providers (Table 2).

\section{Availability of essential drugs, supplies and equipment}

The observation of facilities showed that essential drugs, including antibiotics, intravenous fluids, vaccines and contraceptives were available in the 15 selected facilities. Supplies, like gloves and syringes were also adequate. However, pieces of equipment (number of facilities out of 15 facilities in brackets), including thermometers (5), sphygmomanometers (7), foetoscopes (2), delivery set (5), episiotomy set (5), vacuum extractor (10), blank partograph (7), MVA set (8), bag and mask for neonatal resuscitation (7), sterilizer (5) and refrigerator (8) were either missing or nonfunctional at the time of visiting facilities. Similarly, private consultation rooms (5), delivery room (5), toilet facilities (7), water supply (8) and drainage system in the labor room (13) were unsatisfactory.

\section{Providers training and skills to provide maternal services} Interview with providers directly involved in (assigned to) maternity care at basic obstetric care facilities (health centers and district hospitals) was done to assess providers training and their skills. From the interview, it was found that adequate training or on-the-job experience was obtained by the majority of providers for different types of procedures, including ANC risk screening (89\%), partograph utilization (79\%), intra-venous infusion (97\%), episiotomy (87\%), repairing vaginal tears (82\%), active management of third stage (97\%) and manual removal of placenta (92\%). However, only a limited proportion of providers had adequate training or experience on important procedures, like assisted vaginal delivery (vacuum extraction) (45\%), manual vacuum aspiration (45\%) and evacuation and curettage (26\%) (Table 3).

Most of the interviewed providers claimed that they routinely performed ANC screening procedures, like checking blood pressure, anemia, fetal heartbeat, malaria and HIV. However, only two-fifths, most of them in the hospitals, performed VDRL tests. At the time of delivery care, about $42 \%$ of the providers said that they were checking laboring mothers frequently according to the recommended standard and only $24 \%$ of them were using partograph consistently. Many providers (44\%) never introduced themselves to their clients. Nonetheless, they routinely performed other procedures, like protecting privacy, explaining procedures, informing about the progress of labor and possible outcomes, as well as comforting the laboring mother. The providers did most of the important procedures and counseling at the time of postpartum care but only $68 \%$ of them did 
Table 2 Important service components received by women during their ANC visit and delivery care by types of skilled attendants, North Gondar, 2012

\begin{tabular}{|c|c|c|c|c|c|c|c|c|}
\hline \multirow[t]{3}{*}{ Types of services } & \multicolumn{8}{|c|}{ *Service users by qualification of their provider } \\
\hline & \multicolumn{2}{|c|}{ Doctor } & \multicolumn{2}{|c|}{ Health officer } & \multicolumn{2}{|c|}{ Midwife/Nurse } & \multicolumn{2}{|c|}{ Total } \\
\hline & Yes & $\%$ & Yes & $\%$ & Yes & $\%$ & Yes & $\%$ \\
\hline \multicolumn{9}{|c|}{ Services received by women during their ANC visits by a skilled attendant } \\
\hline Medical history evaluated & 19 & 82.6 & 19 & 86.4 & 425 & 86.2 & 463 & 86.1 \\
\hline Blood pressure measured & 19 & 82.6 & 18 & 81.8 & 390 & 79.1 & 427 & 79.4 \\
\hline Weight measured & 18 & 78.3 & 20 & 90.9 & 375 & 76.1 & 413 & 76.8 \\
\hline Blood sample taken & 17 & 73.9 & 19 & 86.4 & 349 & 70.8 & 385 & 71.6 \\
\hline Urine sample taken & 9 & 39.1 & 11 & 50.0 & 168 & 34.1 & 188 & 34.9 \\
\hline$\pi$ immunization provided & 9 & 39.1 & 10 & 45.5 & 223 & 44.8 & 242 & 45.0 \\
\hline Anti malaria drugs provided & 9 & 39.1 & 10 & 45.5 & 211 & 42.8 & 230 & 42.8 \\
\hline Iron/folic acid provided & 15 & 65.2 & 15 & 68.2 & 315 & 63.9 & 345 & 64.1 \\
\hline Expected due date told & 10 & 43.5 & 12 & 54.5 & 244 & 49.5 & 266 & 49.4 \\
\hline Nutrition advise provided & 16 & 69.6 & 16 & 72.7 & 302 & 61.3 & 334 & 62.1 \\
\hline Fetal growth updated & 10 & 43.5 & 12 & 54.5 & 292 & 59.2 & 314 & 58.4 \\
\hline Birth preparedness discussed & 11 & 47.8 & 11 & 50.0 & 250 & 50.7 & 272 & 50.6 \\
\hline Needed materials for delivery discussed & 9 & 39.1 & 12 & 54.5 & 242 & 49.1 & 263 & 48.9 \\
\hline Place of birth discussed & 15 & 65.2 & 15 & 68.2 & 300 & 60.9 & 330 & 61.3 \\
\hline Advised to go health facility at time of birth & 16 & 69.6 & 14 & 63.6 & 304 & 61.7 & 334 & 62.1 \\
\hline Saving funds discussed & 7 & 30.4 & 12 & 54.5 & 224 & 45.4 & 243 & 45.2 \\
\hline Discussion on danger signs & 9 & 39.1 & 14 & 63.6 & 258 & 52.3 & 281 & 52.2 \\
\hline Discussions on complications during delivery or postpartum & 11 & 47.8 & 12 & 54.5 & 254 & 51.5 & 277 & 51.5 \\
\hline Discussed to go Health facility at time of complication & 15 & 65.2 & 14 & 63.6 & 254 & 51.5 & 283 & 52.6 \\
\hline Discussed to prepare blood donor & 9 & 39.1 & 10 & 45.5 & 183 & 37.1 & 202 & 37.5 \\
\hline Discussed on HIV testing & 17 & 73.9 & 19 & 86.4 & 348 & 70.6 & 384 & 71.4 \\
\hline Discussed about PMTCT & 13 & 56.5 & 17 & 77.3 & 347 & 70.4 & 377 & 70.1 \\
\hline Discussed about other STls & 8 & 34.8 & 8 & 36.4 & 233 & 47.3 & 249 & 46.3 \\
\hline Total & 23 & 100 & 22 & 100 & 493 & 100 & 538 & 100 \\
\hline \multicolumn{9}{|c|}{ Services received by women during their delivery care by a skilled attendant } \\
\hline General health assessment & 28 & 80.0 & 20 & 87.0 & 151 & 87.3 & 199 & 86.1 \\
\hline Blood pressure \& other vital signs & 29 & 82.9 & 17 & 73.9 & 138 & 79.8 & 184 & 79.7 \\
\hline Per vaginal examination & 28 & 80.0 & 17 & 73.9 & 140 & 80.9 & 185 & 80.1 \\
\hline Abdominal examination & 31 & 88.6 & 21 & 91.3 & 158 & 91.3 & 210 & 90.9 \\
\hline Auscultation of fetal heart beat & 31 & 88.6 & 21 & 91.3 & 153 & 88.4 & 205 & 88.7 \\
\hline Control bleeding by drugs & 28 & 80.0 & 22 & 95.7 & 134 & 77.5 & 184 & 79.7 \\
\hline Information on progress of labor & 28 & 80.0 & 17 & 73.9 & 136 & 78.6 & 181 & 78.4 \\
\hline Keep comfort of mother & 29 & 82.9 & 20 & 87.0 & 132 & 76.3 & 181 & 78.4 \\
\hline Give care for the baby & 26 & 74.3 & 17 & 73.9 & 124 & 71.7 & 167 & 72.3 \\
\hline Measure and record baby weight & 18 & 51.4 & 15 & 65.2 & 121 & 69.9 & 154 & 66.7 \\
\hline Give vaccine for baby & 27 & 77.1 & 14 & 60.9 & 118 & 68.2 & 159 & 68.8 \\
\hline Advise about breast feeding & 27 & 77.1 & 17 & 73.9 & 137 & 79.2 & 181 & 78.4 \\
\hline Advise on infant care & 21 & 60.0 & 12 & 52.2 & 94 & 54.9 & 127 & 55.0 \\
\hline Total & 35 & 100 & 23 & 100 & 173 & 100 & 231 & 100 \\
\hline
\end{tabular}

*Number of service users who said "Yes" during the interview and percentage within type of their provider was calculated. 
Table 3 Number and percent of skilled providers having training or on-the-job experience for different types of procedures, North Gondar, 2012

\begin{tabular}{|c|c|c|c|c|c|c|}
\hline \multirow[t]{3}{*}{ Type of procedures } & \multicolumn{6}{|c|}{ Qualification of provider } \\
\hline & \multicolumn{2}{|c|}{ Health officer $(n=9)$} & \multicolumn{2}{|c|}{ Nurse/midwife $(n=29)$} & \multicolumn{2}{|c|}{ Total $(n=38)$} \\
\hline & $\mathrm{n}$ & $\%$ & $\mathrm{n}$ & $\%$ & $\mathrm{n}$ & $\%$ \\
\hline ANC risk screening & 8 & 88.9 & 26 & 89.7 & 34 & 89.5 \\
\hline Partograph utilization & 7 & 77.8 & 23 & 79.3 & 30 & 78.9 \\
\hline IV infusion & 9 & 100 & 28 & 96.6 & 37 & 97.4 \\
\hline Speculum examination & 7 & 77.8 & 15 & 51.7 & 22 & 57.9 \\
\hline Bimanual examination & 8 & 88.9 & 19 & 65.5 & 27 & 71.1 \\
\hline Compress uterus & 7 & 77.8 & 20 & 69.0 & 27 & 71.1 \\
\hline External version & 1 & 11.1 & 4 & 13.8 & 5 & 13.2 \\
\hline Internal version & 0 & 0 & 3 & 10.3 & 3 & 7.9 \\
\hline Episiotomy & 9 & 100 & 24 & 82.8 & 33 & 86.8 \\
\hline Repairing cervical laceration & 0 & 0 & 5 & 17.2 & 5 & 13.2 \\
\hline Repairing vaginal tears & 8 & 88.9 & 23 & 79.3 & 31 & 81.6 \\
\hline Repairing third/fourth degree tear & 1 & 11.1 & 11 & 37.9 & 12 & 31.6 \\
\hline Active management of third stage & 9 & 100 & 28 & 96.6 & 37 & 97.4 \\
\hline Manual removal of placenta & 9 & 100 & 26 & 89.7 & 35 & 92.1 \\
\hline Assisted vaginal delivery (Vacuum extraction) & 6 & 66.7 & 11 & 37.9 & 17 & 44.7 \\
\hline Manual vacuum aspiration & 6 & 66.7 & 11 & 37.9 & 17 & 44.7 \\
\hline Evacuation and curettage & 5 & 55.6 & 5 & 17.2 & 10 & 26.3 \\
\hline
\end{tabular}

vaginal examination. Moreover, many providers reported that they had the skills to manage common obstetric complications, like preeclampsia (68\%), severe bleeding (95\%), retained placenta (97\%), and post-abortion complications (68\%) (Table 4).

\section{Discussion}

The study showed that maternity and related services, including antenatal and delivery care were available in most of the visited facilities. However, the majority of the facilities were not fully functioning for emergency obstetric care (EmOC) according to their level. In health centers (basic EmOC facilities), parenteral anticonvulsants and assisted vaginal delivery were often missing. In the hospitals, cesarean section and blood transfusion were not available. Evidences showed that these functions were commonly unavailable in many other areas $[9,20]$. Only one hospital met the criteria for comprehensive EmOC (performed cesarean section). This hospital is serving about three million people of the zone and the surrounding areas. It has been recommended that for every 500,000 population at least one comprehensive EmOC facility is required [7]. According to this standard, more (about six) facilities fulfilling the signal functions of comprehensive EmOC are needed. The finding implies that many mothers living in distant $(>100 \mathrm{~km}$ ) districts were obliged to travel long distance to get a functional facility at the time of complications.
The findings also indicated that many pregnant women who developed obstetric complications were not benefiting from their care.

Understanding how facilities are actually functioning is more useful than how they are supposed to function. Functioning obstetric facility means performing the essential services for normal situations and performing each signal functions for complications, and these services are available 24 hours a day and 7 days a week. Such functions require enabling environment like facilities and skilled professionals. In many of the visited facilities, important pieces of equipment were either missing or not functional. Most of the health centers also lacked important laboratory tests such as VDRL, hemoglobin, urine protein, and cross match. The absence of such tests has a clear effect on screening services during maternity care. This was a common challenge identified by other studies [21]. Moreover, many of the interviewed midlevel providers had no adequate training on important procedures, like assisted vaginal delivery (vacuum extraction), manual vacuum aspiration or evacuation and curettage. The use of partograph to monitor labor progress helps to take life saving action in a timely manner. However, few providers used partograph consistently. In addition, about one-third had no skill to manage preeclampsia and postabortion complications. Training deficiencies and skill retention problems were among the major bottlenecks 
Table 4 Reports of skilled care providers in the past three months performing the following procedures to women who present for maternity care, North Gondar, 2012

\begin{tabular}{|c|c|c|c|c|c|c|}
\hline \multirow[t]{3}{*}{ Types of services } & \multicolumn{6}{|c|}{ Qualification of provider } \\
\hline & \multicolumn{2}{|c|}{ Health officer $(n=9)$} & \multicolumn{2}{|c|}{ Nurse/midwife $(n=29)$} & \multicolumn{2}{|c|}{ Total $(n=38$} \\
\hline & $\mathrm{n}$ & $\%$ & n & $\%$ & $\mathbf{n}$ & $\%$ \\
\hline \multicolumn{7}{|c|}{ Routinely perform the following steps/check-up to women who present for antenatal care } \\
\hline Take medical history & 9 & 100 & 29 & 100 & 38 & 100 \\
\hline Check BP & 9 & 100 & 29 & 100 & 38 & 100 \\
\hline Check anemia & 9 & 100 & 29 & 100 & 38 & 100 \\
\hline Check fetal heart beat & 9 & 100 & 29 & 100 & 38 & 100 \\
\hline Provide iron/folic acid supplement & 8 & 88.9 & 27 & 93.1 & 35 & 92.1 \\
\hline Check malaria & 9 & 100 & 28 & 96.6 & 37 & 97.4 \\
\hline Test proteinuria & 7 & 77.8 & 20 & 69.0 & 27 & 71.1 \\
\hline Test syphilis & 4 & 44.4 & 11 & 37.9 & 15 & 39.5 \\
\hline Counsel on self care & 9 & 100 & 27 & 93.1 & 36 & 94.7 \\
\hline Counsel on delivery plan & 9 & 100 & 29 & 100 & 38 & 100 \\
\hline Discuss nutrition & 9 & 100 & 29 & 100 & 38 & 100 \\
\hline Tell due date & 9 & 100 & 29 & 100 & 38 & 100 \\
\hline Discuss funds for expense & 6 & 66.7 & 26 & 89.7 & 32 & 84.2 \\
\hline Discuss on transport & 9 & 100 & 23 & 79.3 & 32 & 84.2 \\
\hline Discuss on blood donors & 4 & 44.4 & 18 & 62.1 & 22 & 57.9 \\
\hline Discuss VCT & 9 & 100 & 27 & 93.1 & 36 & 94.7 \\
\hline Discuss PMTCT & 9 & 100 & 26 & 89.7 & 35 & 92.1 \\
\hline \multicolumn{7}{|l|}{ Routinely perform the following at the time of delivery care } \\
\hline Checking laboring mother frequently according to the recommended standard & 5 & 55.6 & 11 & 37.9 & 16 & 42.1 \\
\hline Partograph use at least once & 5 & 55.6 & 14 & 48.3 & 19 & 50.0 \\
\hline Partograph use almost always & 4 & 44.4 & 5 & 17.2 & 9 & 23.7 \\
\hline Introducing for client & 4 & 44.4 & 18 & 62.1 & 22 & 57.9 \\
\hline Allow family to enter & 9 & 100 & 25 & 86.2 & 34 & 89.5 \\
\hline Protecting privacy by screen/clothes & 9 & 100 & 28 & 96.6 & 37 & 97.4 \\
\hline Explain procedures & 8 & 88.9 & 27 & 93.1 & 35 & 92.1 \\
\hline Tell the progress of labor & 9 & 100 & 28 & 96.6 & 37 & 97.4 \\
\hline Tell about possible outcomes & 8 & 88.9 & 26 & 89.7 & 34 & 89.5 \\
\hline Keep comfort of laboring mother & 9 & 100 & 29 & 100 & 38 & 100 \\
\hline Advise to have postpartum care ( $\left.1^{\text {st }} w \mathrm{k}\right)$ & 6 & 66.7 & 15 & 51.7 & 21 & 55.3 \\
\hline \multicolumn{7}{|l|}{ Routinely perform the following at the time of postpartum care } \\
\hline Abdominal examination & 9 & 100 & 24 & 82.8 & 33 & 86.8 \\
\hline Vaginal examination & 8 & 88.9 & 18 & 62.1 & 26 & 68.4 \\
\hline Checking BP & 9 & 100 & 29 & 100 & 38 & 100 \\
\hline Assessing abnormal bleeding & 9 & 100 & 29 & 100 & 38 & 100 \\
\hline Inspection of lochia & 9 & 100 & 26 & 89.7 & 35 & 92.1 \\
\hline Discussing FP & 9 & 100 & 29 & 100 & 38 & 100 \\
\hline Advise BF & 9 & 100 & 29 & 100 & 38 & 100 \\
\hline Checking baby & 9 & 100 & 27 & 93.1 & 36 & 94.7 \\
\hline
\end{tabular}


Table 4 Reports of skilled care providers in the past three months performing the following procedures to women who present for maternity care, North Gondar, 2012 (Continued)

\begin{tabular}{|c|c|c|c|c|c|c|}
\hline \multicolumn{7}{|c|}{ Management of selected complications } \\
\hline Preclampsia & 8 & 88.9 & 18 & 62.1 & 26 & 68.4 \\
\hline Severe bleeding & 9 & 100 & 27 & 93.1 & 36 & 94.7 \\
\hline Retained placenta & 9 & 100 & 28 & 96.6 & 37 & 97.4 \\
\hline Post abortion care & 7 & 77.8 & 19 & 65.5 & 26 & 68.4 \\
\hline
\end{tabular}

to have quality maternal care in many developing countries [11,22].

Providing incomplete (poor quality) maternal service had damaging effect on health-seeking behavior of mothers. The linked data analysis, as continuation of this study, indicated that utilization of skilled maternal care by individual woman depends on the joint effect of individual, household, communal and facility characteristics. Our analysis indicated that the presence of all the six signal functions in the nearby basic essential obstetric care facility (health center) positively contributed to the utilization of all indicators of skilled maternal services, and its effect was significant on skilled attendance rate [23].

According to the interview with mothers who received antenatal care from skilled providers, most of their service was at health centers by nurses or midwives. They rarely used doctors or specialists. After criticisms on the traditional ANC (the risk approach), the new approach that is focused antenatal care emphasizes the quality of service. In this study, the implementations of the important components of ANC services were incomplete. Many mothers did not receive various antenatal screening services. Tetanus immunization, iron supplementation, counseling and advice on nutrition, birth preparedness and readiness for possible complication were lower than expected. The identified gap in all areas of service components indicated that the current antenatal care service could be challenged to achieve the goal of focused ANC.

Like the ANC, many women who had delivery care by a skilled attendant did not receive important services. To more than $20 \%$ of the mothers' services, like blood pressure measurement, information on labor progress, and drugs for preventing bleeding were not provided. For more than $30 \%$ of the mothers, baby weight was not measured and vaccine was not provided. Providers also paid little attention to counseling and advice on different types of maternal and childcare. In this regard, the poor skills of providers may be the main causes of the unsatisfactory services. In many developing countries, competency and skill retention of providers are the major concerns for skilled birth attendance [12,24].

This study has had certain limitations. During the interview, for example, women faced difficulties to differentiate types of skilled providers. To minimize the problem, data collectors did further clarifications by collecting information on types of providers from health institutions that gave the services. Because of the crosssectional design of the study, recall and interviewer bias were also potential limitations. However, numerous scientific procedures were employed to minimize the possible effects. To reduce the recall bias, for instance, only women who gave birth in the last one year were included.

In conclusion, maternity services including antenatal and delivery care by a skilled provider were available in most of the visited facilities. However, components of both the routine and emergency maternity care services were incomplete. The majority of the facilities were not fully functioning for EmOC according to their level. The implementations of the important components of ANC and delivery services were incomplete and thus, many mothers did not receive various components of the services. The findings suggested that providing incomplete (poor quality) maternal service is the country's major challenge to achieve the MDG target of reducing maternal mortality. Improving the functional capacity of health facilities for the delivery of routine maternity and EmOC services are needed. According to evidence of other countries, it will be good to focus on interventions, like renovations and upgrading facilities, provision of essential equipment, and on-job training of staff $[18,25]$.

\section{Competing interests}

The authors declare that they have no competing interests.

\section{Authors' contributions}

All authors contributed equally during the process of proposal development. $A G$ and AW participated in data collection and analysis. AG prepared the draft. Then AW and MF revised drafts of the paper. All authors read and approved the final manuscript.

\section{Acknowledgements}

We are very grateful to Addis Ababa University for the approval of the ethical clearance and its technical and financial support. We would like to thank all of the study participants including facility managers, health care providers, and clients for their commitment in responding to our interviews and to our data collectors for their extensive devotion at fieldwork.

\section{Author details}

${ }^{1}$ Department of Reproductive Health, Institute of Public Health, University of Gondar, Gondar, Ethiopia. ${ }^{2}$ Department of Preventive Medicine, School of Public Health, Addis Ababa University, Addis Ababa, Ethiopia. ${ }^{3}$ Department of Reproductive Health and Health Service Management, School of Public Health, Addis Ababa University, Addis Ababa, Ethiopia. 
Received: 17 February 2013 Accepted: 20 August 2013

Published: 23 August 2013

\section{References}

1. Ethiopia CSA, ICFinternational: Ethiopia demographic and health survey 2011 Maryland, USA: Addis Ababa, Ethiopia and Calverton; 2012.

2. Gage AJ: Barriers to the utilization of maternal health care in rural Mali. Soc Sci Med (1982) 2007, 65(8):1666-1682.

3. Tlebere $P$, Jackson D, Loveday M, Matizirofa L, Mbombo N, Doherty T, Wigton A, Treger L, Chopra M: Community-based situation analysis of maternal and neonatal care in south Africa to explore factors that impact utilization of maternal health services. J Midwifery Wom Health 2007, 52(4):342-350.

4. Tsui A, Ukwuani F, Guilkey D, Angeles G: A comparative multi-level analysis of health program effects on individual use of reproductive and sexual health services. MEASURE Evaluation Bulletin 2003, 6:1-12.

5. Gabrysch S, Cousens S, Cox J, Campbell OMR: The influence of distance and level of care on delivery place in rural Zambia: a study of linked national data in a geographic information system. PLoS Med 2011, 8(1):e1000394

6. Paxton A, Bailey P, Lobis S, Fry D: Global patterns in availability of emergency obstetric care. Int I Gynaecol Obstet: the official organ of the International Federation of Gynaecology and Obstetrics 2006, 93(3):300-307.

7. World Health Organization, UNICEF, UNFPA and AMDD: Monitoring Emergency Obstetric Care: A Handbook. WHO, UNICEF, UNFPA and AMDD; 2009.

8. $\mathrm{MOH}$, Ethiopia: Health Sector Development Programme N. Addis Ababa: $\mathrm{MOH} ; 2011$.

9. Bailey P, Paxton A, Lobis S, Fry D: The availability of life-saving obstetric services in developing countries: an in-depth look at the signal functions for emergency obstetric care. Int J Gynaecol Obstet: the official organ of the International Federation of Gynaecology and Obstetrics 2006, 93(3):285-291.

10. Rose M, Abderrahim N, Stanton C, Helsel D: Maternity care: A comparative report on the availability and use of maternity services, MEASURE Evaluation Technical Report Series.; 2001. No.9.

11. Harvey SA, Ayabaca P, Bucagu M, Djibrina S, Edson WN, Gbangbade S, McCaw-Binns A, Burkhalter BR: Skilled birth attendant competence: an initial assessment in four countries, and implications for the safe motherhood movement. Int J Gynecol Obstet 2004, 87(2):203-210.

12. Harvey SA, Blandón YCW, McCaw-Binns A, Sandino I, Urbina L, Rodríguez C, Gómez I, Ayabaca P, Djibrinaf S, group tNmanhqi: Are skilled birth attendants really skilled? A measurement method, some disturbing results and a potential way forward. Bull World Health Organ 2007, 85:783-790.

13. Olsen BE, Hinderaker SG, Bergsjø P, Lie RT, Olsen OHE, Gasheka P, Kvåle G: Causes and characteristics of maternal deaths in rural northern Tanzania. Acta Obstet Gynecol Scand 2002, 81(12):1101-1109.

14. Kerber KJ, Graft-Johnson JE, Bhutta ZA, Okong P, Starrs A, Lawn JE: Continuum of care for maternal, newborn, and child health: from slogan to service delivery. Lancet 2007, 370:1358-1369.

15. WHO: A Global Review of the Key Interventions Related to Reproductive, Maternal, Newborn and Child Health (RMNCH), Interventions, commodities, and guidelines for Reproductive, Maternal, Newborn and Child Health. Geneva, Switzerland: WHO; 2011.

16. Turner AG, Angeles G, Tsui AO, Wilkinson M, Magnani R: Sampling Manual for Facility Surveys for Population, Maternal Health, Child Health and STD Programs in Developing Countries. Carolina Population Center, University of North Carolina at Chapel Hill: MEASURE Evaluation; 2001.

17. FDRE PCCO: Statistical Report of the 2007 Population and Housing Census of Ethiopia Results. Addis Ababa: UNFPA, Population Census Commission; 2008.

18. Carlough M, McCall M: Skilled birth attendance: what does it mean and how can it be measured? A clinical skills assessment of maternal and child health workers in Nepal. Int J Gynaecol Obstet: the official organ of the International Federation of Gynaecology and Obstetrics 2005, 89(2):200-208.

19. WHO: Making pregnancy safer: The critical role of the skilled attendant, A joint statement by WHO, ICM and FIGO. Department of Reproductive Health and Research. Geneva: WHO; 2004 [http://www.who.int/maternal_child_ adolescent/documents/9241591692/en/index.html]

20. Ameh C, Msuya S, Hofman J, Raven J, Mathai M, van den Broek N: Status of emergency obstetric care in six developing countries five years before the MDG targets for maternal and newborn health. PloS one 2012 7(12):e49938.

21. Jahn A, Dar lang M, Shah U, Diesfeld HJ: Maternity care in rural Nepal: a health service analysis. Trop Med Int Health: TM \& IH 2000, 5(9):657-665.

22. Ith P, Dawson A, Homer C: Quality of maternity care practices of skilled birth attendants in Cambodia. Int J Evid Based Healthc 2012, 10(1):60-67.

23. Worku AG, Yalew AW, Afework MF: Factors affecting utilization of skilled maternal care in northwest Ethiopia: a multilevel analysis. BMC Int Health and Human Rights 2013, 13(1):20.

24. Darmstadt GL, Lee ACC, Cousens S, Sibley L, Bhutta ZA, Donnay F, Osrin D, Bang A, Kumar V, Wall SN, et al: 60 million non-facility births: who can deliver in community settings to reduce intrapartum-related deaths? Int J Gynecol Obstet: the official organ of the International Federation of Gynaecology and Obstetrics 2009, 107(Suppl 1):S89-S112.

25. Kayongo M, Butera J, Mboninyibuka D, Nyiransabimana B, Ntezimana A, Mukangamuje V: Improving availability of EmOC services in RwandaCARE's experiences and lessons learned at Kabgayi referral hospital. Int J Gynecol Obstet: the official organ of the International Federation of Gynaecology and Obstetrics 2006, 92(3):291-298.

doi:10.1186/1742-4755-10-43

Cite this article as: Worku et al:: Availability and components of maternity services according to providers and users perspectives in North Gondar, northwest Ethiopia. Reproductive Health 2013 10:43.

\section{Submit your next manuscript to BioMed Central and take full advantage of:}

- Convenient online submission

- Thorough peer review

- No space constraints or color figure charges

- Immediate publication on acceptance

- Inclusion in PubMed, CAS, Scopus and Google Scholar

- Research which is freely available for redistribution 